\title{
Outcome of cataract surgery in patients with retinitis pigmentosa
}

\author{
H Jackson, D Garway-Heath, P Rosen, A C Bird, S J Tuft
}

\begin{abstract}
Aim-To determine the visual benefit of cataract extraction in patients with retinitis pigmentosa and to identify risk factors for poor outcome.

Methods-A retrospective analysis was undertaken of a continuous series of 142 eyes of 89 patients with retinitis pigmentosa undergoing cataract surgery between 1985 and 1997.

Results-Mean age at surgery was 47.5 years (range 24-81 years). In 100 eyes there was posterior subcapsular lens opacity alone, 37 eyes also had moderate nuclear sclerosis, and five had only nuclear sclerosis. All patients had central visual fields of $<10^{\circ}$. Overall, mean visual acuity improved from 1.05 (SD 0.38) preoperatively to 0.63 (SD 0.49 ) postoperatively on the $\log$ MAR scale. Significant postoperative capsular opacification occurred in $88 / 139$ eyes $(63 \%)$ and $45.1 \%$ required capsulotomy. Anterior capsulotomy was undertaken in $5 / 52(9.6 \%)$ eyes undergoing phacoemulsification. Postoperative macular oedema was noted in $20(14 \%)$ eyes. Visual acuity improved in 109 eyes $(77 \%)$, was unchanged in 29 eyes $(20.5 \%)$, and worsened after surgery in four eyes $(2.5 \%)$. $86 / 89$ patients reported major improvement of visual function.

Conclusions-Cataract surgery for relatively minor lens opacities is beneficial in patients with retinitis pigmentosa, and most report subjective improvement of visual symptoms. The incidence of capsular opacification is high and anterior capsular contraction may occur. The number of eyes with poor vision due to macular oedema was unexpectedly low.

(Br F Ophthalmol 2001;85:936-938)
\end{abstract}

Ophthalmology,

Institute of

Ophthalmology,

Cayton Street, London

EC1V 9EL, UK

H Jackson

A C Bird

Moorfields Eye Hospital, City Road, London EC1V 2PD, UK

D Garway-Heath

P Rosen

S J Tuft

Correspondence to: Miss H Jackson, West Ken Eye Centre, Farnborough Hospital, Bromley BR6 8ND, UK

Accepted for publication 5 December 2000
(2) Macular oedema is a common complication of RP, occurring in approximately $10-15 \%$ of patients, ${ }^{45}$ although a prevalence of up to
$70 \%$ has been reported on fluorescein angiography. ${ }^{67}$ Macular oedema (Irvine Gass syndrome) develops in approximately $1 \%$ of normal patients after cataract surgery using current surgical techniques, ${ }^{8}$ and it might therefore be expected that cataract surgery would precipitate or exacerbate macular oedema in patients with RP.

(3) There is a risk of phototoxic retinal damage in normal patients undergoing cataract extraction. ${ }^{9}$ The threshold for light damage is probably lower in RP, which could adversely affect visual outcome.

(4) Posterior capsular opacification and anterior capsular contraction is more aggressive in the presence of $R P,{ }^{10-19}$ The reason for the increased cellular proliferation on the capsular remnant in retinal dystrophies is unknown, although the cellular nature of the posterior capsule in retinal dystrophies may account for this. ${ }^{19-21}$

Despite the potentially poor result in terms of visual acuity, we consider that it is important that patients with RP and cataract are offered early cataract surgery. However, patients should also have realistic expectations of the outcome of surgery. To provide better data on the incidence of these complications and their effect on outcome, and hence the potential risks and benefits of surgery, we have reviewed the records of a large series of patients with RP who had cataract surgery.

\section{Patients and methods}

The records of all patients with RP who had cataract extraction between 1985 and 1997 were assessed retrospectively with regard to age, heredofamilial pattern of RP, visual fields (Goldmann or confrontation if very constricted), morphology of cataract, preoperative and postoperative symptoms and visual acuity, surgical complications, incidence of macular oedema and capsular opacification, and subjective response to surgery. The Snellen visual acuity preoperatively and at the time of discharge from the cataract service was converted to the logMAR scale. Recommendation for surgery was made when the lens opacities were considered as the cause of poor central vision rather than macular changes. Surgery was either by extracapsular or phacoemulsification technique, with the coaxial illumination reduced to the lowest practicable level.

\section{Results}

There were 89 patients (142 eyes) with RP who had cataract surgery between 1985 and 1997 (54 male and 35 female). Mean follow up was 32.7 months (range 1-156 months). The average age at surgery on the first eye was 47.3 
years (range 24-81 years) and 48.9 years for the second eye. Patients with $\mathrm{X}$ linked disease had surgery approximately 10 years earlier than the other groups (Table 1). The most common visual complaint was of glare and blurring of vision in bright light, and all patients had preoperative visual fields of $\leqslant 10^{\circ}$. The predominant cataract morphology in 137 eyes $(96.5 \%)$ was a combined posterior cortical and posterior subcapsular lens opacity; $37(27 \%)$ of these also had some nuclear sclerosis and five eyes only had nuclear sclerosis. The morphology of the cataracts did not differ significantly between heredofamilial groups on clinical examination. Extracapsular cataract extraction and intraocular lens (IOL) implantation was undertaken in $90(63 \%)$ eyes, and the remainder had phacoemulsification and IOL implantation. Three eyes had a posterior capsular rupture during surgery; of these, one had an anterior chamber IOL and two were left aphakic.

\section{VISUAL ACUITY}

The average preoperative $\log$ MAR acuity was 1.05 (SD 0.38), with a range of 0.3-2.2. Only one patient had an acuity of 0.3 or better before surgery. Overall, visual acuity improved to 0.63 (SD 0.49 ) postoperatively on the $\log$ MAR scale, an average improvement of $0.42 \log$ units.

Following surgery, the best spectacle corrected visual acuity improved in 109 eyes $(77 \%)$, was unchanged in 29 eyes $(20.5 \%)$, and worsened in four eyes $(2.5 \%)$. The preoperative visual acuity of the 29 eyes which had no visual improvement following surgery was worse than eyes that improved, with an average preoperative $\log$ MAR acuity of 1.23 (range 0.5-2.2). A subjective improvement of symptoms was reported in $86(96.6 \%)$ patients.

MACULAR OEDEMA

Macular oedema was identified postoperatively in $20(14 \%)$ eyes by fluorescein angiography (Fig 1), and was suspected in a further 15 eyes, although angiography was not undertaken in all these. In those eyes in which postoperative macular oedema was noted, the mean visual acuity still improved from 0.98 preoperatively to 0.52 postoperatively on the $\log$ MAR scale. Macular oedema that was not noted preoperatively was present in all four eyes in which the visual acuity deteriorated after surgery; in one eye this only developed after exchange of an IOL that dislocated following a YAG laser anterior capsulotomy.

CAPSULE OPACIFICATION

There was a high incidence of posterior capsular opacification. YAG laser capsulotomy was performed in 60/139 (43.2\%) eyes, but this incidence increased to $51 \%$ in those eyes with

Table 1 Heredofamilial type of RP and age at surgery

\begin{tabular}{lllcl}
\hline & $\begin{array}{l}\text { Autosomal } \\
\text { dominant }\end{array}$ & $\begin{array}{l}\text { Autosomal } \\
\text { recessive }\end{array}$ & X linked & $\begin{array}{l}\text { Simplex (no } \\
\text { family history) }\end{array}$ \\
\hline Number & 27 & 26 & 6 & 33 \\
Mean age at surgery (years) & 48.4 & 46.3 & 36.3 & 49.5 \\
\hline
\end{tabular}
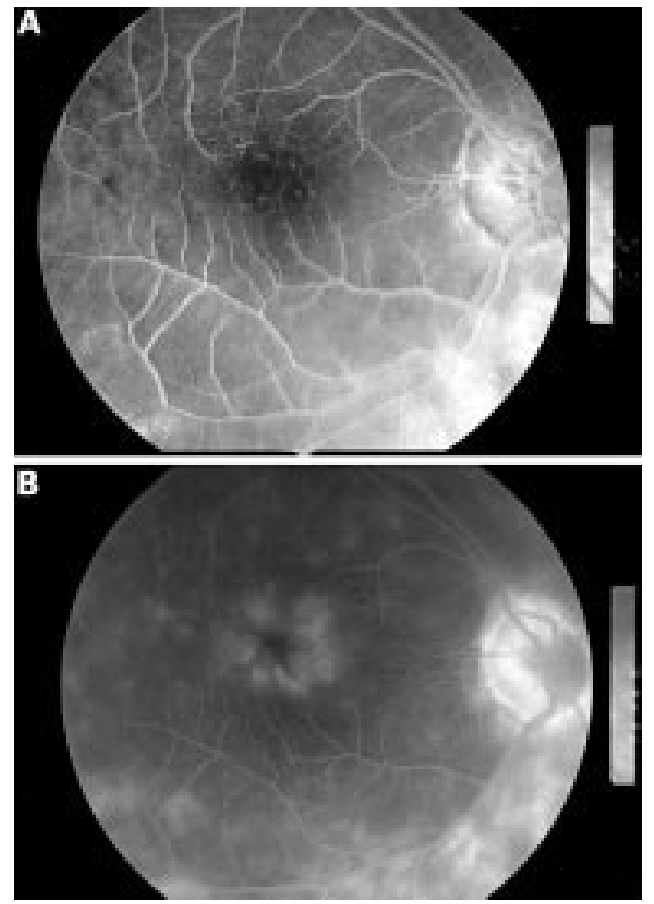

Figure 1 Macular oedema in a patient with RP. (A) Early phase of fluorescein angiogram, $(B)$ late phase of fluorescein angiogram.

more than 6 months of follow up (118 eyes). A further 28 eyes had capsular thickening which was not considered sufficient to cause visual impairment or there was macular oedema that might have been aggravated by intervention. Five patients with anterior capsular contraction required either a surgical or a YAG laser anterior capsulotomy.

\section{Discussion}

Patients with RP typically develop a combined posterior cortical and posterior subcapsular cataract which, when combined with a restricted central visual field, may cause significant additional visual disability even when the opacity appears to be relatively minor. Glare is a major symptom and patients may require cataract extraction at a relatively young age. The mean age at surgery of $47-58$ years in previous studies ${ }^{13-16}{ }^{19}$ and 47.5 years in our study compares with the mean age at surgery of 72.5 years for age related cataract at this institution. ${ }^{22}$ The age at surgery was lower in patients with X linked RP in our study.

The visual acuity in $23 \%$ of eyes did not improve after surgery, and their preoperative visual acuity was worse than the group as a whole. Postoperatively, the majority of these eyes had confirmed or suspected macular oedema but we could not exclude preoperative macular oedema in all of these cases. Macular oedema in RP can be difficult to diagnose owing to the extremely slow leak of fluorescein on angiography, irregular pigmentation at the level of the retinal pigment epithelium, and the reluctance of the ophthalmologist to subject the patient to the bleaching effect of the procedure. In all four cases in which the visual acuity deteriorated following surgery macular oedema was documented, although in one case 
this only occurred after secondary intraocular surgery. The incidence of postoperative macular oedema was lower than we had expected.

Over $96 \%$ of patients reported a functional improvement in their visual symptoms following surgery despite the acuity being unchanged or worse in almost a quarter of eyes. This suggests that other measures of visual function may be indicated when assessing patients with $\mathrm{RP}$ for cataract surgery and evaluating benefit.

The high incidence of capsule opacification $(63 \%)$ in this series is comparable with other reports. ${ }^{13}$ Not all of these eyes have had a capsulotomy, either because of the pre-existence of suspected macular oedema or because it was considered that the capsular opacity was not sufficient to reduce visual function. As 24 eyes had less than 6 months of follow up it is probable that final percentage requiring capsulotomy will be higher. The reason for the high incidence of posterior capsular opacification in patients with RP is not understood, but mediators released by the neurosensory retina may modify lens fibre growth and differentiation. ${ }^{11}$ It has been suggested that the abnormal retina causes a hypercellular posterior capsule and the characteristic posterior cataract in $\mathrm{RP},{ }^{12}{ }^{19-21}$ and as this is not influenced by surgery continued cellular growth might be expected. Similar stimuli may cause the contraction of the anterior capsulorhexis that was observed in five of the $52(9.6 \%)$ eyes that had phacoemulsification, leading to dislocation of the foldable plate-haptic silicone IOL into the anterior chamber in one case. This risk has been previously identified. ${ }^{10}{ }^{18}{ }^{23}$ Hayashi et al reported a $45 \%$ decrease in the anterior capsule opening at 6 months after surgery in patients with RP compared with a decrease of $4.6 \%$ in a control group. ${ }^{18}$

It is evident from our series that patients with RP benefit from early cataract surgery, and that the vast majority have a subjective improvement in their symptoms of glare. The benefit of surgery for patients with a poor preoperative visual acuity is less marked, usually because of pre-existing macular disease, but postoperative macular oedema was less common than expected. Patients with RP appear to be susceptible to anterior capsule contraction and therefore a small capsulorhexis should be avoided. It would appear to be sensible to avoid silicone IOLs because of the risk of their dislocation if an early capsulotomy is required.

1 Pruett RC. Retinitis pigmentosa: clinical observations and Pruett RC. Retinitis pigmentosa: clinical observations and 735 .

2 Fishman GA, Anderson RJ, Loureco P. Prevalence of posterior subcapsular lens opacities in patients with retinitis pigmentosa. Br f Ophthalmol 1985; 69:263-6.

3 Heckenlively J. The frequency of posterior subcapsular cataract in the hereditary retinal degenerations. $\mathrm{Am} \mathcal{F} \mathrm{Oph}$ thalmol 1982;93:733-8.

4 Fishman GA, Gilbert DG, Fiscella RG, et al. Acetazolamide for treatment of chronic macular oedema in retinitis pigmentosa. Arch Ophthalmol 1989;107:1445-52.

5 Spalton DJ, Bird AC, Cleary PE. Retinitis pigmentosa and retinal oedema. Br f Ophthalmol 1978;62:174

6 Newsome DA. Retinal fluorescein leakage in retinitis pigmentosa. Am f Ophthalmol 1986;101:354-60.

7 Fetkenhour CL, Choromokos E, Weinstein J, et al. Cystoid macular oedema in retinitis pigmentosa. Trans Am Acad Ophthmol Otolaryngol 1977;83:515-21.

8 Gass JDM, Norton EWD. Cystoid macular edema and papilledema following cataract extraction. A fluorescein fundoscopic and angiographic study. Arch Ophthalmol 1966;76:646-61

9 Lee BL, Sternberg JP. Microscope light toxicity. Sem Ophthalmol 1993; 8:151-5.

10 Nishi O, Nishi N. Intraocular lens encapsulation by shrinkage of the capsulorrhexis opening. I Cataract Refract Surg 1993; 19:544-5.

11 Nishi O, Nishi K, Fujisawa T, et al. Effects of cytokines on the proliferation of and collagen synthesis by human cataract lens epithelial cells. Br f Ophthalmol 1996;80:63-8.

12 Eshaghian J, Rafferty N, Goosens W. Ultrastructure of human cataract in retinitis pigmentosa. Arch Ophthalmol 1980;98:2227-30.

13 Auffarth GU, Tetz MR, Krastel H, et al. Indikationen und erfolgsaussichten der kataraktoperation bei patienten mit retinitis pigmentosa. Ophthalmologe 1996;93:168-76.

14 Bastek JV, Heckenlively JR, Straatsma BR. Cataract surgery in retinitis pigmentosa patients. Ophthalmology 1982;89: $880-4$.

15 Reccia R, Scala A, Bosone G. Posterior chamber intraocular lens implantation in patients with retinitis pigmentosa. Doc Ophthalmol 1989;72:115-8

16 Newsome DA, Stark WJ, Maumanee IH. Cataract extraction and intraocular lens implantation in patients with retinitis pigmentosa or Usher's syndrome. Arch Ophthalmol 1986;104: 852-4.

17 Auffarth GU, Nimsgern C, Tetz MR, et al. Erhohte nachstarrate und besonderheiten der ND:YAG-
laserkapsulotomie bei retinitis pigmentosa. Ophthalmologe 1997;94:791-5.

18 Hayashi K, Hayashi H, Matsuo K, et al. Anterior capsule contraction and intraocular lens dislocation after implant surgery in eyes with retinitis pigmentosa. Ophthalmology 1998;105:1239-43.

19 Fagerholm PP, Philipson BT. Cataract in retinitis pigmentosa. An analysis of cataract surgery results and pathologitosa. An analysis of cataract surgery results and path
cal lens changes. Acta Ophthalmol 1985;63:50-8.

20 Streeten BW, Eshagian J. Human posterior subcapsular cataract. A gross and flat preparation study. Arch Ophthalmol 1978;96:1653-8

21 Al-ghoul KJ, Novak LA, Kuszak JR. The structure of posterior subcapsular cataracts in the Royal College of Surgeons (RCS) rats. Exp Eye Res 1998;67:163-77.

22 Murphy C, Tuft SJ, Minassian D. Visual acuity and refractive error following cataract extraction: an outcome study. Brf Ophthalmol 2001 (submitted).

23 Tuft SJ, Talks SJ. Delayed dislocation of foldable platehaptic silicone lenses after Nd:YAG laser anterior capsulotomy. Am f Ophthalmol 1998;126:586-8. 